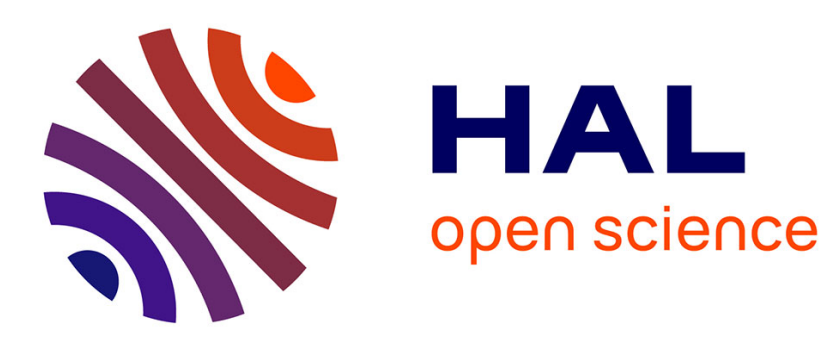

\title{
Photoacoustic and photothermal detection of photosensitized oxygenations
}

P. Poulet, A. Salnick, J. Szurkowski, J. Chambron

\section{To cite this version:}

P. Poulet, A. Salnick, J. Szurkowski, J. Chambron. Photoacoustic and photothermal detection of photosensitized oxygenations. Journal de Physique IV Proceedings, 1994, 04 (C7), pp.C7-473-C7-476. 10.1051/jp4:19947110 . jpa-00253163

\section{HAL Id: jpa-00253163 https://hal.science/jpa-00253163}

Submitted on 1 Jan 1994

HAL is a multi-disciplinary open access archive for the deposit and dissemination of scientific research documents, whether they are published or not. The documents may come from teaching and research institutions in France or abroad, or from public or private research centers.
L'archive ouverte pluridisciplinaire HAL, est destinée au dépôt et à la diffusion de documents scientifiques de niveau recherche, publiés ou non, émanant des établissements d'enseignement et de recherche français ou étrangers, des laboratoires publics ou privés. 


\title{
Photoacoustic and photothermal detection of photosensitized oxygenations
}

\author{
P. Poulet, A. Salnick, J. Szurkowski* and J. Chambron \\ URA 1173 du CNRS, Institut de Physique Biologique, Faculté de Médecine, 67085 Strasbourg cedex, \\ France \\ * Institute of Experimental Physics, University of Gdansk, 80-952 Gdansk, Poland
}

\begin{abstract}
Study of relaxation processes of excited states of hematoporphyrin IX (HP) solutions (in ethanol and methanol) in the presence of tetramethyl ethylene chemical acceptor using both the photoacoustic (PA) - microphone - and photothermal (PT) - PZT - detection, is described. A significant difference between PA and PT signal behaviour has been observed when extremely low (down to $1.25 \mu \mathrm{M}$, PT measurements) and high (up to $2.5 \mathrm{mM}$, PA measurements) concentrations of sensitizer were used.
\end{abstract}

\section{INTRODUCTION}

Recently there has been a growing interest in quantitative analysis of singlet oxygen, $\mathrm{O}_{2}\left({ }^{1} \Delta_{\mathrm{g}}\right)$, production and deactivation mechanisms, as it is generally recognised that tumor destruction in photodynamic therapy is achieved via singlet oxygen formation and its reactions with cellular substrates $\left({ }^{1}\right)$. We had demonstrated the efficiency of the photoacoustic (PA) method when applied to the measurements of photophysical properties of molecules in highly concentrated solutions which relax through a metastable state $\left({ }^{2}\right)$, in particular when singlet oxygen relaxation pathways are altered by chemical acceptors $\left({ }^{3}\right)$. In this paper, results of both, PA and photothermal (PT) - PZT - studies of relaxation processes of hematoporphyrin IX (HP) sensitizer solutions in two, very different, concentration ranges : $[\mu \mathrm{M}(\mathrm{PT})$ and $\mathrm{mM}(\mathrm{PA})]$ are presented and initial attempts to quantitate data discussed.

\section{THEORY}

The ratio $\Gamma$ of the signal amplitude with chemical acceptor to the signal amplitude without acceptor has been calculated for PA and PT detection. For PA method, which is sensitive to all prompt and delayed heat, $\Gamma$ could be presented by $(2,3)$ :

$$
\Gamma=1-\frac{\gamma_{\Delta} \gamma_{4} E_{4}}{E_{e x}-\gamma_{f} E_{f}} \quad \text { or } \frac{1}{1-\Gamma}=\alpha\left(1+\frac{\beta}{[C]}\right)
$$

where $E_{e x}$ is absorbed photon energy, $\gamma_{f}$ is the quantum yield of fluorescence, $E_{f}$ is the mean fluorescence photon energy, $\gamma_{\Delta}$ is the quantum yield of singlet oxygen production, $\gamma_{4}$ is the quantum yield for chemical reaction : $\gamma_{4}=\mathrm{k}_{\mathrm{r}}[\mathrm{C}] /\left(\mathrm{k}_{\mathrm{d}}+\mathrm{k}_{\mathrm{r}}[\mathrm{C}]\right)$. Here, [C] is the acceptor concentration, $\mathrm{k}_{\mathrm{d}}$ represents the conversion rate of singlet oxygen by physical reaction with the solvent, $\mathrm{k}_{\mathrm{r}}[\mathrm{C}]$ is the conversion rate of singlet oxygen through chemical reaction with the acceptor and $E_{4}$ is the energy of the product. Quantities $\alpha$ and $\beta$ in 
Eq(1) are defined as : $\alpha=\left(E_{e x}-\gamma_{f} E_{f}\right) / \gamma_{\Delta} E_{4}$ and $\beta=k_{d} / k_{r}$.

The above relations between $\Gamma$ and concentration of the acceptor can be used to adjust experimental results. A three parameter fit used for PA experiment analysis, amplitude at $[C]=0, \alpha$ and $\beta$ was found to give more accurate results than a linear fit. For PT, which is sensitive to prompt heat and to the part of the delayed heat produced in a time shorter than the acoustic transit time $\tau_{a}\left({ }^{4}\right)$, the ratio $\Gamma$ is a complex expression of above parameters, the energy of singlet oxygen $E_{\Delta}$ and the ratio of acoustic transit time $\tau_{a}$ to lifetime of singlet oxygen in the presence of acceptor $\tau_{\Delta}=1 /\left(k_{d}+k_{r}[C]\right)$. At high acceptor concentration $\left(\tau_{\mathrm{a}}>\tau_{\Delta}\right.$ and $\left.\gamma_{4}=1\right) \Gamma_{\infty}$, a limit of ratio $\Gamma$, can be expressed as :

$$
\Gamma_{\infty}=1+\frac{\gamma_{\Delta}\left(E_{\Delta} e^{-\tau_{a} k_{d}}-E_{4}\right)}{E_{e x}-\gamma_{f} E_{f}-\gamma_{\Delta} E_{\Delta} e^{-\tau_{a} k_{d}}}=1+\frac{1}{\alpha^{\prime}}
$$

In order to measure $\Gamma_{\infty}$, the model for PA was used to fit our results. The fitted parameters comprise amplitude at $[C]=0, \alpha^{\prime}$, and $\beta^{\prime}$ which are depending on $\mathrm{k}_{\mathrm{d}} / \mathrm{k}_{\mathrm{r}}$ and $\tau_{\mathrm{a}} \mathrm{k}_{\mathrm{r}}$. The coefficient $\alpha^{\prime}$ depends on the part of energy stored in the singlet oxygen state and converted into heat by physical quenching during the acoustic transit time. If $\tau_{\mathrm{a}} \mathrm{k}_{\mathrm{d}} \gg 1, \mathrm{Eq}(1)$ can be used for PT experiments $\left(\alpha^{\prime}=\alpha\right)$ whilst in the opposite case, $\left(\tau_{\mathfrak{a}} k_{d}<<1\right), \alpha^{\prime}=\left(E_{e x}-\gamma_{f} E_{f}-\gamma_{\Delta} E_{\Delta}\right) / \gamma_{\Delta}\left(E_{4}-E_{\Delta}\right)$.

\section{MATERIALS AND METHODS}

The PA spectrometer with Xe-arc lamp and gas-microphone PA-cell used in this study has been slightly modified in comparison to that reported earlier ( 2 ). Experiments with various acceptor concentrations have shown that $\Gamma$ is independent of the modulation frequency (up to $500 \mathrm{~Hz}$ ) and that the phase of the signal does not depend on [C]. Spectral analyses were performed at $40 \mathrm{~Hz}$. A dye laser $(384 \mathrm{~nm})$ pumped by a nitrogen laser and a cell with ceramic PZT-detector (Max Planck Institut für Strahlenchemie, Mülheim an der Ruhr, Germany) have been used in the PT study. A beam $2 \mathrm{~mm}$ in diameter was used, giving an acoustic transit time $\tau_{\mathrm{a}}$ of about $2 \mu \mathrm{s}$. The HP was dissolved to reach concentration of $2.5 \mu \mathrm{M}$ (PZT) and $2.5 \mathrm{mM}$ (PA) both in ethanol and methanol without any additional purification. The $\mathrm{O}_{2}\left({ }^{1} \Delta_{\mathrm{g}}\right)$ specific acceptor - tetrametyl ethylene (TME) - was added at concentrations ranging from 5 to $400 \mathrm{mM}$. Optical density measurements (transmission spectroscopy) were performed in order to control optical absorption coefficient.

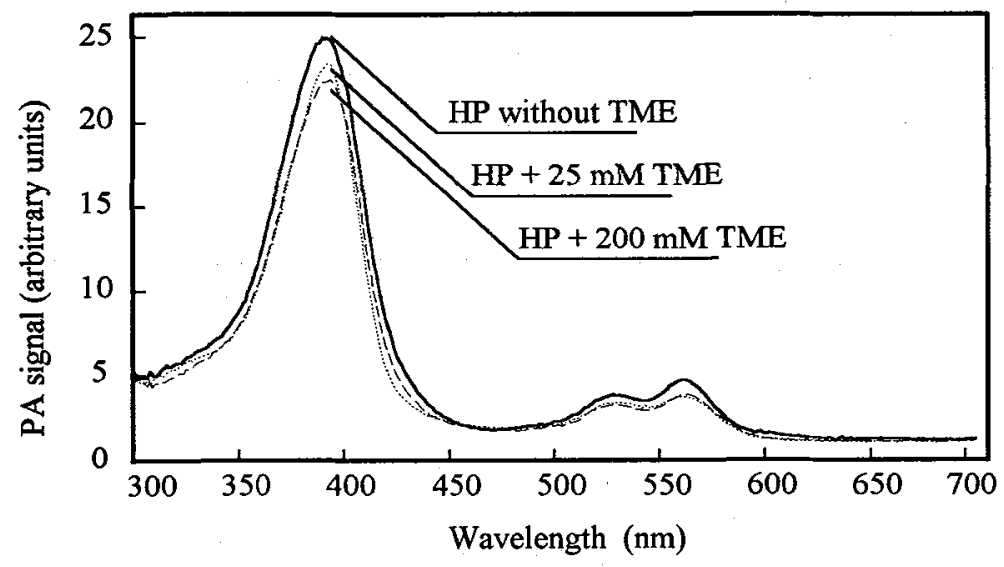

Figure 1 : The normalized PA spectra of $\mathrm{HP}$ in ethanol $(2.5 \mathrm{mM})$ with and without TME acceptor. 


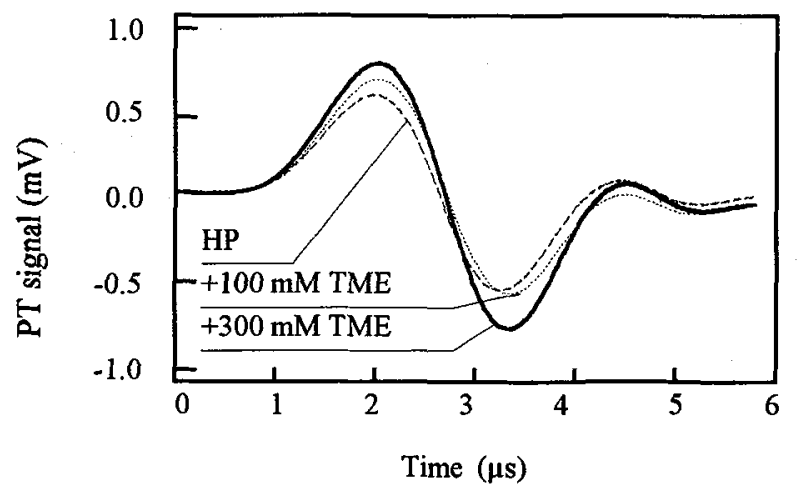

Figure 2 : Experimental PZT waveforms at $384 \mathrm{~nm}$ for HP solution in ethanol $(2.5 \mu \mathrm{M})$ with and without TME.

\section{EXPERIMENTAL RESULTS}

\subsection{PA measurements}

Fig. 1 shows the PA spectra of HP in ethanol, without acceptor, and in the presence of TME for two different acceptor concentrations. Drops in PA amplitude (as a function of increasing acceptor concentration) are observed in the absorption bands. For other wavelengths precision of our measurements did not allow calculation of ratio $\Gamma$. A strong decrease in $\Gamma$ was obtained as the concentration of acceptor increased from $5 \mathrm{mM}$ to $400 \mathrm{mM}$, when the PA cell was filled with air. For a cell loaded with nitrogen $\Gamma$ remained equal to 1 , demonstrating that the acceptor reacts with singlet oxygen. Experiments with different HP concentrations (down to $0.3 \mathrm{mM}$ ), and other dye (methylene blue) or chemical acceptor (furfuryl alcohol) produced similar results.

\subsection{PZT measurements}

Fig. 2 shows the PZT waveforms for pure HP solution in ethanol and in presence of TME at two different concentrations, the value of $\Gamma$ was calculated from the amplitude corresponding to the first maximum. Larger $\Gamma$ was obtained as the TME concentration increased, in contrast to PA results, where a decrease in $\Gamma$ was observed at $395 \mathrm{~nm}$. Identical PT results were obtained when working with the HP solutions in methanol, or with other dyes or chemical acceptors.

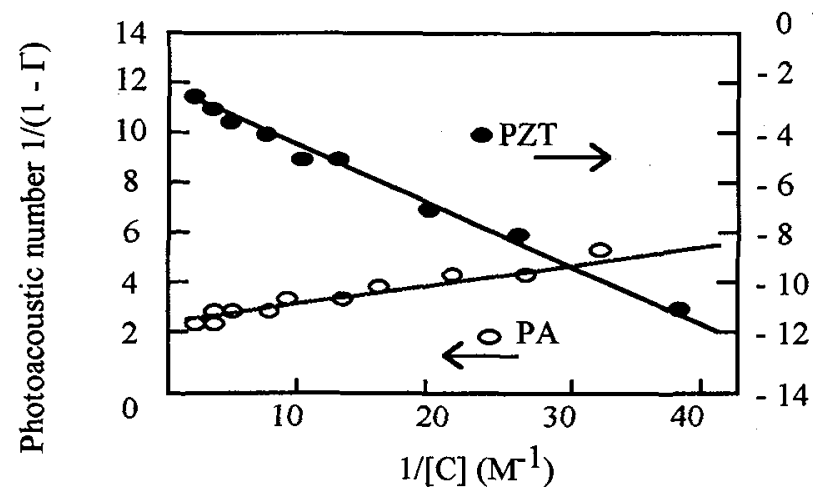

Figure 3 : Experimental results and regression fits (lines) showing the photoacoustic number $1 /(1-\Gamma)$ versus $[C]$ for $\mathrm{HP}$ in ethanol measured with PT ( HP $2.5 \mu \mathrm{M}$ ) and PA (HP $2.5 \mathrm{mM}$ ) detection. 
Table1 : Results of adjusting experimental results obtained with the PA and PT methods for some solutions in alcohol.

\begin{tabular}{lccccc}
\hline Sample & Detection & $\alpha$ & $\alpha^{\prime}$ & $\beta(\mathrm{mM})$ & $\beta^{\prime}(\mathrm{mM})$ \\
\hline HP, 2.5 $\mu \mathrm{M}$ (methanol) & PZT & & -2.21 & & 109 \\
HP, 2.5 $\mu$ (ethanol) & PZT & & -2.17 & & 210 \\
HP, 2.5 mM (ethanol) & PA & 3.36 & & 15 & \\
\hline
\end{tabular}

\section{DISCUSSION}

The linear variations of the photoacoustic number $1 /(1-\Gamma)$ versus the inverse of acceptor concentration for both PT and PA studies are shown in Fig. 3 together with the results of the adjustments to the theoretical model given by $\mathrm{Eq}(1)$. The adjusted parameters are presented in Table 1 . For PT experiments, only the fitted coefficient $\alpha^{\prime}$ can be interpreted. Using the known values for photophysical parameters $: \mathrm{E}_{\mathrm{ex}}-\gamma_{\mathrm{f}} \mathrm{E}_{\mathrm{f}}=$ $3.05 \mathrm{eV}$ for $\mathrm{HP}$ and assuming acetone as the final product of TME photooxydation : $\mathrm{E}_{4}=-1.8 \mathrm{eV}$, one can estimate the quantum yield of singlet oxygen production $\gamma_{\Delta}$. Assuming $\tau_{\mathrm{a}} \mathrm{k}_{\mathrm{d}} \gg 1, \gamma_{\Delta}$ calculated from $\mathrm{Eq}(1)$ or $\mathrm{Eq}(2)$ were 0.42 for $\mathrm{HP}$ in methanol and 0.43 for HP in ethanol. Assuming $\tau_{\mathrm{a}} \mathrm{k}_{\mathrm{d}} \ll 1$, the quantum yields $\gamma_{\Delta}$ calculated from $\mathrm{Eq}(2)$ were 0.76 in methanol and 0.78 in ethanol. The accepted (0.5) value for $\gamma_{\Delta}\left({ }^{5}\right)$ corresponds to $\tau_{\mathrm{a}} \mathrm{k}_{\mathrm{d}}=0.43$ for methanol and 0.36 for ethanol. Using the known values for $\mathrm{k}_{\mathrm{d}}: 10^{5} \mathrm{~s}^{-1}$ in methanol and $6.610^{4} \mathrm{~s}^{-1}$ in ethanol $\left(^{6}\right)$, it is possible to estimate the effective acoustic transit time (4.3 $\mu$ s and $5.5 \mu \mathrm{s}$ in methanol and ethanol respectively). This approach can be considered as a way to measure the time response of the spectrometer.

The experimental results from PA experiments yielded positive values for $\alpha$ corresponding to negative values of $\gamma_{\Delta} \mathrm{E}_{4}$ product and cannot be interpreted with the presently accepted theoretical model. The difference observed between PA and PT signal behaviour- i.e., a decrease and an increase in $\Gamma$ with increasing acceptor concentration, can be related to significant difference in concentrations, leading to oxygen consumption and diffusion processes not taken into account here. More complex relaxation pathways like type I and type II photosensitizations and singlet oxygen - sensitizer interactions should also be considered. The first PT experiments reported above seem to provide a new approach for observation of singlet oxygen production and relaxation. Quantitative measurements of photophysical parameters $\left(\gamma_{\Delta}, \mathrm{E}_{4}\right.$ and $\left.\mathrm{k}_{\mathrm{r}}\right)$ require more precise theoretical studies. These, and the experimental verifications, are currently being considered.

\section{ACKNOWLEDGEMENTS}

This work was supported by the Association pour la Recherche contre le Cancer (ARC) under grant 41592. One of authors (J.S.) is also thankful for the fellowship received by Commission of the European Communities. Translation work of Miss Heider and technical assistance provided by Mrs Chabrier are greatly acknowledged.

\section{REFERENCES}

[1] Kessler D., Photochem. Photobiol. 39 (1984) 851-859.

[2] Ouzafe M., Poulet P. and Chambron J., Photochem. Photobiol. 55 (1992) 491-503.

[3] Salnick A., Ouzafe M., Poulet P. and Chambron J., Biochem. Biophys. Res. Comm. 192 (1993) 198203.

[4] Braslavsky S.E. and Heibel G.E., Chem. Rev. 92 (1992) 1381-1410.

[5] Redmond R.W., Heihoff K., Braslavsky S.E. and Truscott T.G., Photochem. Photobiol. 45 (1987) 209-213.

[6] Rodgers M.A.J., J. Am. Chem. Soc. 105 (1983) 6201-6205 